\title{
CHOLINERGIC AGONIST-ANTAGONIST INTERACTIONS ON NEOCORTICAL AND LIMBIC EEG ACTIVATION*
}

\author{
KEN-ICHI Yamamoto $†$ and EDWARD F. Domino \\ Department of Pharmacolugy, University of Michigan, Ann Arbor, Michigan
}

(Accepted 16 March 1967)

\begin{abstract}
Summary-The effects of various cholinergic agonists and antagonists and their interactions were determined on the awake-sleep cycle of cats with chronic indwelling brain electrodes. The effects were measured by the use of the EEG and correlated with gross behavioral observation. EEG recordings were taken from various neocortical and limbic structures, including the amygdala and hippocampus.

EEG activation and behavioral arousal following acetylcholine $(0.007 \mathrm{mg} / \mathrm{kg})$ intravenously was blocked by pretreatment with the muscarinic $(m)$ cholincrgic antagonists methyl atropine and atropine $(0.3 \mathrm{mg} / \mathrm{kg})$. On the other hand this was not affected by the nicotinic $(n)$ ganglionic cholinergic antagonists trimethidinium $(1 \mathrm{mg} / \mathrm{kg})$ and mecamylamine $(0.7 \mathrm{mg} / \mathrm{kg})$. EEG activation and behavioral arousal produced by arecoline $(0.4 \mathrm{mg} / \mathrm{kg})$ was reduced slightly by methyl atropine and completely blocked by atropine, but not modified by trimethidinium and mecamylamine. EEG activation and behavioral arousal produced by pilocarpine $(0.15 \mathrm{mg} / \mathrm{kg})$ was significantly reduced by methyl atropine and almost completely abolished by atropine. On the other hand, EEG activation produced by pilocarpine was not significantly blocked by the $n$ cholinergic antagonists. Pilocarpine caused a significant increase in the duration of fast wave sleep. It also produced an interesting phenomenon in which fast wave sleep frequently started from the resting state or followed a short drowsy period in contrast to its usual initiation from slow wave sleep. EEG activation and behavioral arousal were observed following physostigmine. These effects were reduced by methyl atropine and almost completely blocked by atropine. The $n$ cholinergic antagonists did not show any significant effect on physostigmine-induced EEG activation and behavioral arousal. Fast wave sleep following physostigmine was also occasionally observed starting from the drowsy state. There was no increase in fast wave sleep in comparison to saline solution injection within 50 min following physostigmine. EEG activation and behavioral arousal were produced by nicotine $(0.02 \mathrm{mg} / \mathrm{kg})$. These effects were not altered significantly by methyl atropine, but moderately reduced by atropine. In addition, atropine produced a dissociation in which nicotine-induced EEG activation of the neocortex was still evident although hippocampal and amygdaloid activation were blocked. The EEG actions of nicotine were slightly reduced by trimethidinium and completely blocked by the administration of mecamylamine.

It is concluded that this study provides additional evidence for the role of $m$ and $n$ ganglionic cholinergic mechanisms in EEG activation of neocortical and limbic structures.
\end{abstract}

\section{INTRODUCTION}

A GREAT deal of evidence implicates cholinergic mechanisms in EEG activation. RINALDI and HIMWICH (1955) suggested that the mesodiencephalic system of rabbits was cholinergic. Since then a number of investigators using a variety of animals have obtained supporting data. The Russian pharmacologists DENISENKo (1961, 1962), ILYUTCHENOK and coworkers (1961, 1962), MiKHELSON (1961), VALDMAN $(1961,1963)$ and others have presented considerable evidence for the presence of muscarinic $(m)$ and nicotinic ganglionic $(n)$

\footnotetext{
*Supported in part by the Michigan Neuropsychopharmacology Research Program, Grant MH-11846, USPHS.

†Present address: Department of Neuropharmacology, Shionogi Research Laboratory, Osaka, Japan.
} 
receptor mechanisms in neocortical EEG activation. Our own data with nicotine (KNAPP and Domino, 1962; and YAMAMoto and Domino, 1965), nicotine and arecoline (VILlaRReAL and Domino, 1964) and related cholinergic agonists have led us to similar conclusions. Especially pertinent is the research of WIKLER (1952), BRADLEY and ELKES (1957), and BRADLEY and NICHOLSON (1962) in which dissociation between the EEG and behavioral manifestations of atropine and physostigmine were reported. It was our purpose to study a series of cholinergic agonists and antagonists on EEG activating mechanisms of neocortical and limbic system structures in cats with chronic indwelling brain electrodes. This manuscript describes the results obtained. A preliminary report of some of the data (Domino et al., 1967) recently has been published.

\section{METHODS}

Experiments were performed in eight adult cats of both sexes with chronic indwelling brain electrodes. An incomplete Latin Square design was used for drug administration at 1 week intervals. The animals were prepared for placement of the brain electrodes using modifications of conventional techniques. Surgical preparation of the animals was under pentobarbital sodium anesthesia. Stainless steel wires of $0.22 \mathrm{~mm}$ dia. (insulated except for the tips of $0.5 \mathrm{~mm}$ ) were used as the depth electrodes. Bipolar depth electrodes were inserted into the amygdala and hippocampus with the aid of the stereotaxic atlases of JASPER and AJMONE-MARSAN (1954), and SNIDER and NIEMER (1961). Physiologic recordings of the injury discharges were used for localization of the hippocampus, and olfactory induced waves for the amygdala. Bipolar silver ball electrodes of $0.5 \mathrm{~mm}$ dia. were applied on the epidural surface of the somatosensory cortex. Additional depth electrodes were placed occasionally in the posterior hypothalamus and mesencephalic reticular formation. Each electrode was soldered to a Cannon plug and fixed on the calvarium by means of dental cement. Silastic tubing of $0.7 \mathrm{~mm}$ dia. was inserted in the right jugular vein with the other end fixed to the connector on top of the skull. The animals were allowed to recover for a 2-week period before being used for the drug studies. In the meantime they were given antibiotics prophylactically to reduce infection. Each animal was given one of the test pretreatment drugs at weekly intervals throughout the entire study. The short acting cholinergic agonists such as acetylcholine, nicotine, pilocarpine, etc., were tested in a random sequence following recovery from the previous drug injection. Thus a variable interval after pretreatment of 20-260 min elapsed. The actual times after injection are given for each experimental record showing typical drug interactions. The overall mean data were in agreement with these typical trends. At the time of the experiment, the EMG of the posterior neck muscles, EKG and respiratory movements were recorded along with brain waves on a Grass polygraph. During the experimental session each animal was placed in a soundproof box with a one way viewing window. Behavior changes were observed and correlated with EEG activity. In order to promote natural sleep the animals were made as warm and as comfortable as possible. With care and patience it was possible to observe all stages of sleep.

The following drugs were administered as an i.v. infusion in physiological saline solution over a 1-min period: acetylcholine chloride, arecoline hydrochloride, atropine sulfate, atropine methylnitrate, pilocarpine hydrochloride, physostigmine salicylate, mecamylamine hydrochloride, and trimethidinium methosulfate. Dosage of all drugs was calculated as base and given in a volume of $1.5 \mathrm{ml}$. After completion of the experiments the 
position of the electrodes was determined histologically by the iron deposition technique (see Domino, 1955, for details). Blood pressure was measured in acute animals prepared under diethyl ether anesthesia and subsequently given a local anesthetic, $1 \mathrm{mg} / \mathrm{kg}$ of decamethonium and artificial respiration at $300 \mathrm{ml}$ of air $/ \mathrm{kg} / \mathrm{min}$.

\section{RESULTS}

\section{Lack of effects of saline infusion on EEG and behavior}

Six different EEG levels can easily be recorded in the chronic cat: excited, alert, resting, drowsy, slow wave and fast wave (activated) sleep. As illustrated in Fig. 1 these EEG states are identified by specific alterations of neocortical and limbic system spontaneous activity. In addition, on the basis of EKG, ocular movements and EMG, the states can be further differentiated. All animals given an i.v. infusion of $1.5 \mathrm{ml}$ of physiologic saline solution warmed to body temperature did not show any change in EEG and behavior.

\section{Effects of various cholinergic antagonists on the awake-sleep cycle}

(1) Atropine sulfate. Depending upon dose, atropine either had no significant effect (less than $0.1 \mathrm{mg} / \mathrm{kg}$, i.v.), facilitated slow wave sleep $(0.3 \mathrm{mg} / \mathrm{kg})$ or prevented natural fast wave sleep and caused behavioral hyperexcitability with continuous EEG slow waves (over $0.6 \mathrm{mg} / \mathrm{kg}$ ). The latter phenomenon of EEG dissociation from overt behavior was similar to that reported by WikLer (1952), BRADLEY and ElKEs (1957), and BradLEY and Nicholson (1962). A dose of $0.3 \mathrm{mg} / \mathrm{kg}$ of atropine was chosen as the amount for pretreatment to study its interaction with various cholinergic agonists. This dose of atropine reduces but does not completely block the depressor response to i.v. cholinergic agonists.

(2) Methyl atropine. In contrast to the marked effects of atropine on EEG and behavior, methyl atropine had much less effect. Doses below $0.6 \mathrm{mg} / \mathrm{kg}$ did not modify the awake-sleep cycle of the cat. However, obvious peripheral physiological manifestations were noted, including dilated pupils and tachycardia. Inasmuch as a dose of 0.3 $\mathrm{mg} / \mathrm{kg}$ of atropine was used, a similar dose of methyl atropine was chosen to study its interaction with cholinergic agonists.

(3) Mecamylamine. The spontaneous awake-sleep cycle of the chronic cat was not affected by doses of mecamylamine below $0.7 \mathrm{mg} / \mathrm{kg}$ i.v. On the other hand doses larger than $1 \mathrm{mg} / \mathrm{kg}$ of mecamylamine interfered with the EEG and behavioral manifestations of slow wave sleep. Usually the cat lay on the floor of the observation chamber and would not fall asleep. Therefore, a dose of $0.7 \mathrm{mg} / \mathrm{kg}$ was chosen in order to study its interaction with various cholinergic agonists.

(4) Trimethidinium. Relatively large doses of trimethidinium had no significant effect on the EEG. Doses below $1 \mathrm{mg} / \mathrm{kg}$ i.v. did not interfere with the awake-sleep cycle but did produce tachycardia. Doses larger than $2 \mathrm{mg} / \mathrm{kg}$ caused the animal to lie on its side on the floor of the cage, and to continue to manifest signs of normal sleep. It was decided to use a dose of $1.0 \mathrm{mg} / \mathrm{kg}$ of trimethidinium as the pretreatment dose to study its interaction with cholinergic agonists.

Interactions of various cholinergic agonists-antagonists on the awake-sleep cycle

(1) Acetylcholine. Increasing doses of acetylcholine were administered until characteristic EEG and behavioral activation was obtained. This occurred consistently with a 

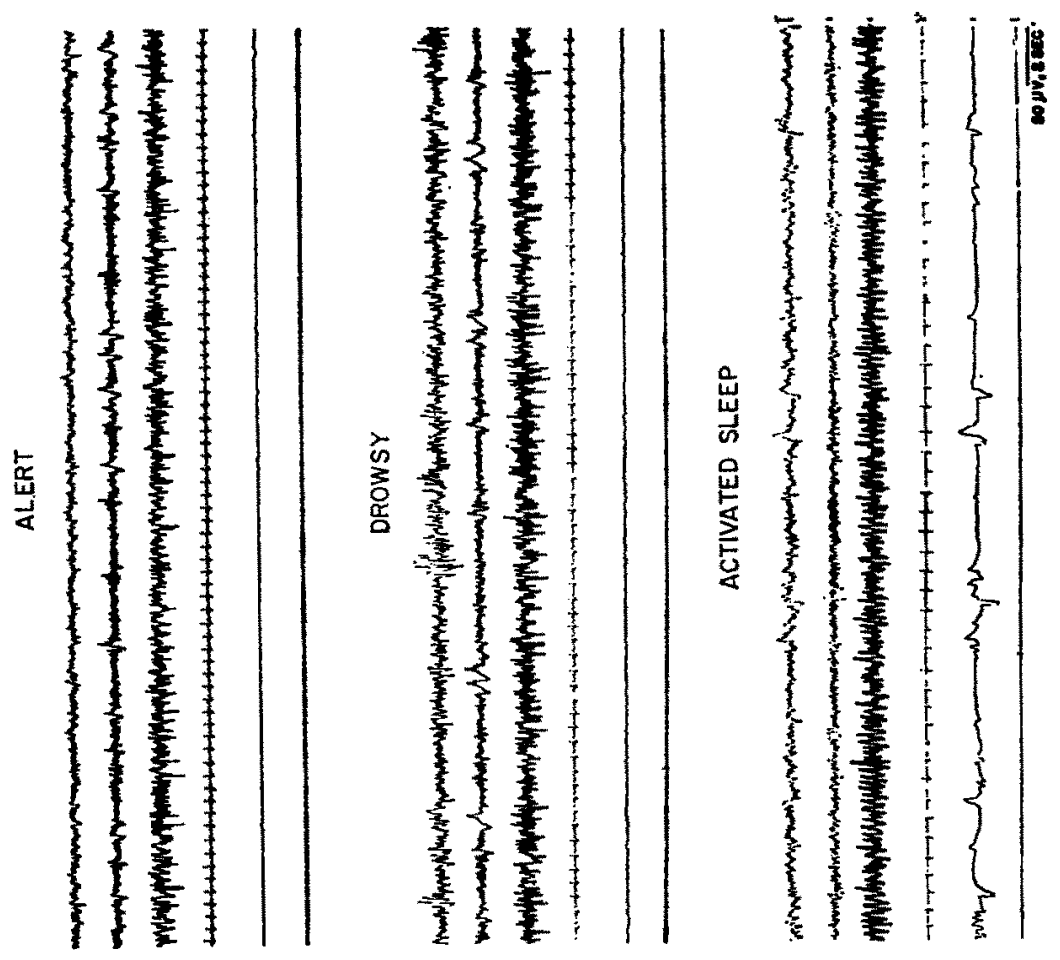

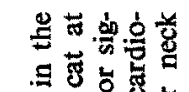

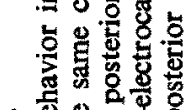

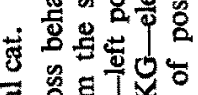

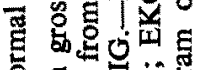

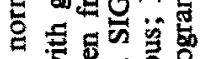

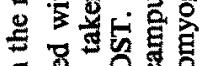

.

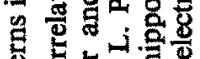

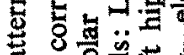

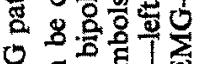

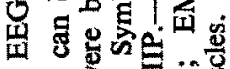
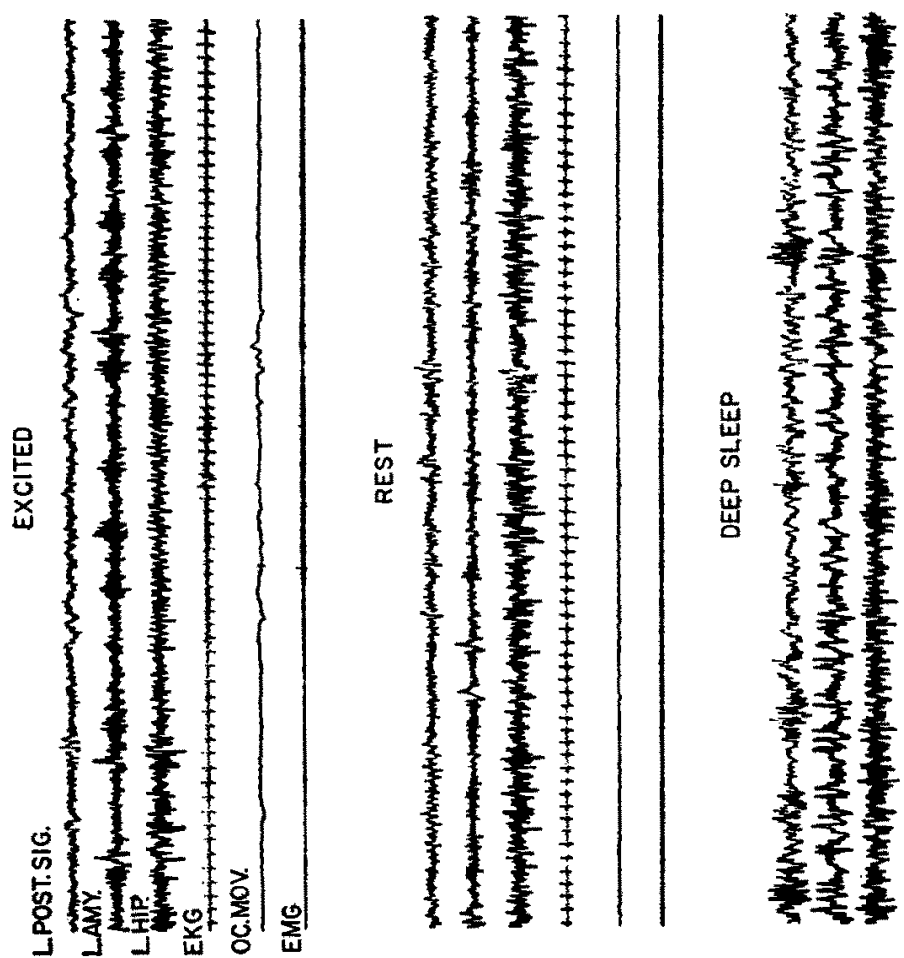

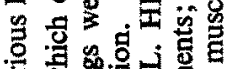

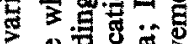

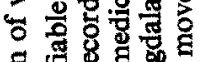

.

鸪

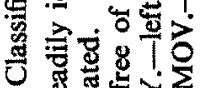

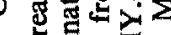

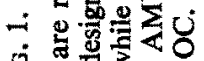

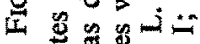

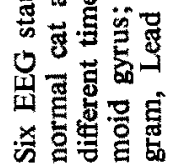


dose of $0.007 \mathrm{mg} / \mathrm{kg}$. With this dose of acetylcholine the blood pressure in decamethoniumimmobilized cats fell approximately $70 \mathrm{~mm} \mathrm{Hg}$. Acctylcholine injection caused behavioral arousal such as opening of the eyes, raising and shaking of the head, etc. in animals who were previously in slow wave sleep. Some cats violently scratched their neck during the period of arousal. Heart and respiratory rates were markedly increased.

Figure 2 is a graphic illustration of the effect of such a large dose of acetylcholine injected i.v. to a sleeping cat. It can be seen that acetylcholine caused a very marked change in respiration, heart rate, a transient period of behavioral arousal and EEG activation which lasted approximately $4 \mathrm{~min}$. In a series of cats the mean duration \pm S.E. of the acetylcholine-induced EEG activation was $4 \cdot 1 \pm 0.5 \mathrm{~min}$ (Table 1).

In Fig. 3 are illustrated graphically the effects of acetylcholine in the same cat as modified

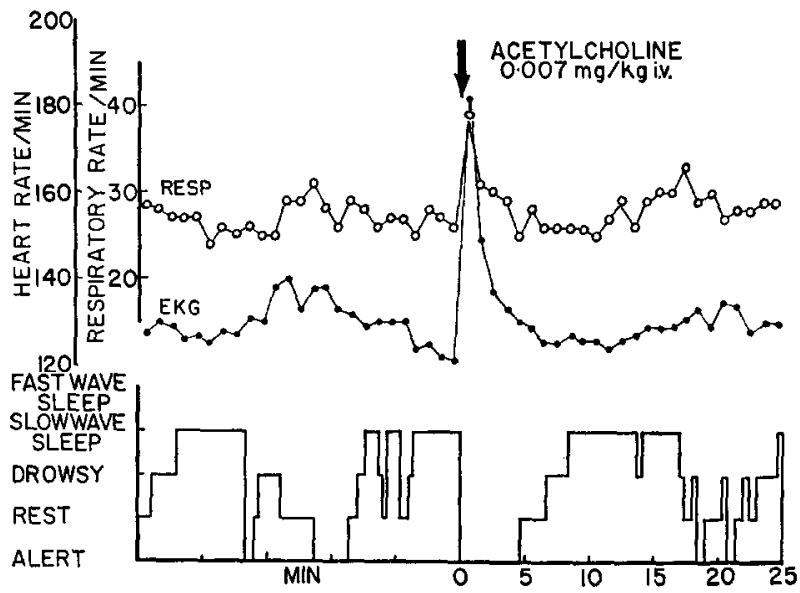

FIG. 2. Graph of the effects of acetylcholine.

Table 1. Mean uURAiION \pm S.E. IN min uF EEG aCtivation Following Various Cholinergic agonistsANTAGONISTS GIVEN i.v.

\begin{tabular}{|c|c|c|c|c|c|c|}
\hline \multirow[b]{2}{*}{ Antagonist } & \multicolumn{5}{|c|}{ Agonist } & \multirow[b]{2}{*}{$\begin{array}{c}\text { Nicotine } \\
0.02 \mathrm{mg} / \mathrm{kg}\end{array}$} \\
\hline & no. of cats & $\begin{array}{l}\text { Acetylcholine } \\
0.007 \mathrm{mg} / \mathrm{kg}\end{array}$ & $\begin{array}{c}\text { Arecoline } \\
0.04 \mathrm{mg} / \mathrm{kg}\end{array}$ & $\begin{array}{l}\text { Pilocarpine } \\
0.15 \mathrm{mg} / \mathrm{kg}\end{array}$ & $\begin{array}{l}\text { Physostigmine } \\
0.05 \mathrm{mg} / \mathrm{kg}\end{array}$ & \\
\hline $\begin{array}{l}0.09 \% \text { Saline } \\
\text { solution }\end{array}$ & & & & & & \\
\hline $1.5 \mathrm{ml}$ & 8 & $4 \cdot 1 \pm 0 \cdot 5$ & $11 \cdot 9 \pm 0 \cdot 8$ & $13 \cdot 3 \pm 1 \cdot 3$ & $31 \cdot 6 \pm 2 \cdot 2$ & $4.7 \pm 0.5$ \\
\hline $\begin{array}{l}\text { Methyl } \\
\text { Atropine } \\
0.3 \mathrm{mg} / \mathrm{kg}\end{array}$ & 6 & $0 \cdot 3 \pm 0 \cdot 1^{*}$ & $9.6 \pm 0.9$ & $2 \cdot 3 \pm 0.2^{*}$ & $22 \cdot 9 \pm 3 \cdot 2 \ddagger$ & $3 \cdot 2 \pm 0 \cdot 3$ \\
\hline $\begin{array}{l}\text { Atropine } \\
0.3 \mathrm{mg} / \mathrm{kg}\end{array}$ & 7 & $0 \cdot 1 \pm 0 \cdot 1^{*}$ & $0 \cdot 2 \pm 0 \cdot 1^{*}$ & $0^{*}$ & $1 \cdot 3 \pm 0.5^{*}$ & $2 \cdot 1 \pm 0 \cdot 3 \dagger$ \\
\hline $\begin{array}{l}\text { Trimethidinium } \\
1.0 \mathrm{mg} / \mathrm{kg}\end{array}$ & 5 & $4 \cdot 5 \pm 0 \cdot 7$ & $15 \cdot 0 \pm 2 \cdot 8$ & $15 \cdot 9 \pm 2 \cdot 4$ & $29 \cdot 7 \pm 5 \cdot 1$ & $2 \cdot 7 \pm 0 \cdot 2$ \\
\hline $\begin{array}{l}\text { Mecamylamine } \\
0.7 \mathrm{mg} / \mathrm{kg}\end{array}$ & 6 & $6 \cdot 9+1 \cdot 2 \ddagger$ & $13 \cdot 7+1 \cdot 8$ & $21 \cdot 8+2 \cdot 0 \dagger$ & $30 \cdot 2 \pm 3 \cdot 4$ & $0 \cdot 1 \pm 0 \cdot 2^{*}$ \\
\hline
\end{tabular}

Student " $t$ " test group comparison
$* P<0.001$
$+P<0.01$
$\ddagger P<0.05$ 

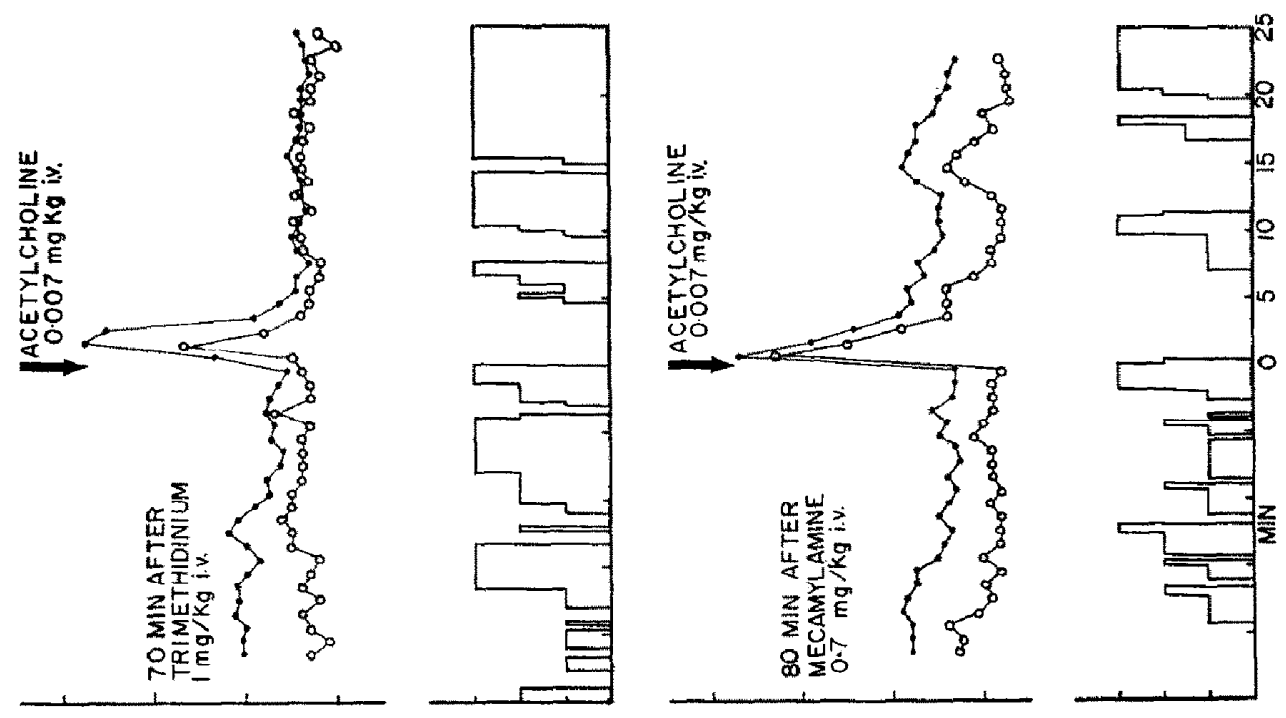

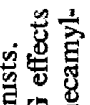
吅 밈묘 空 总 든 음 을 훙. 을 要: 宫要

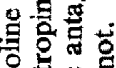
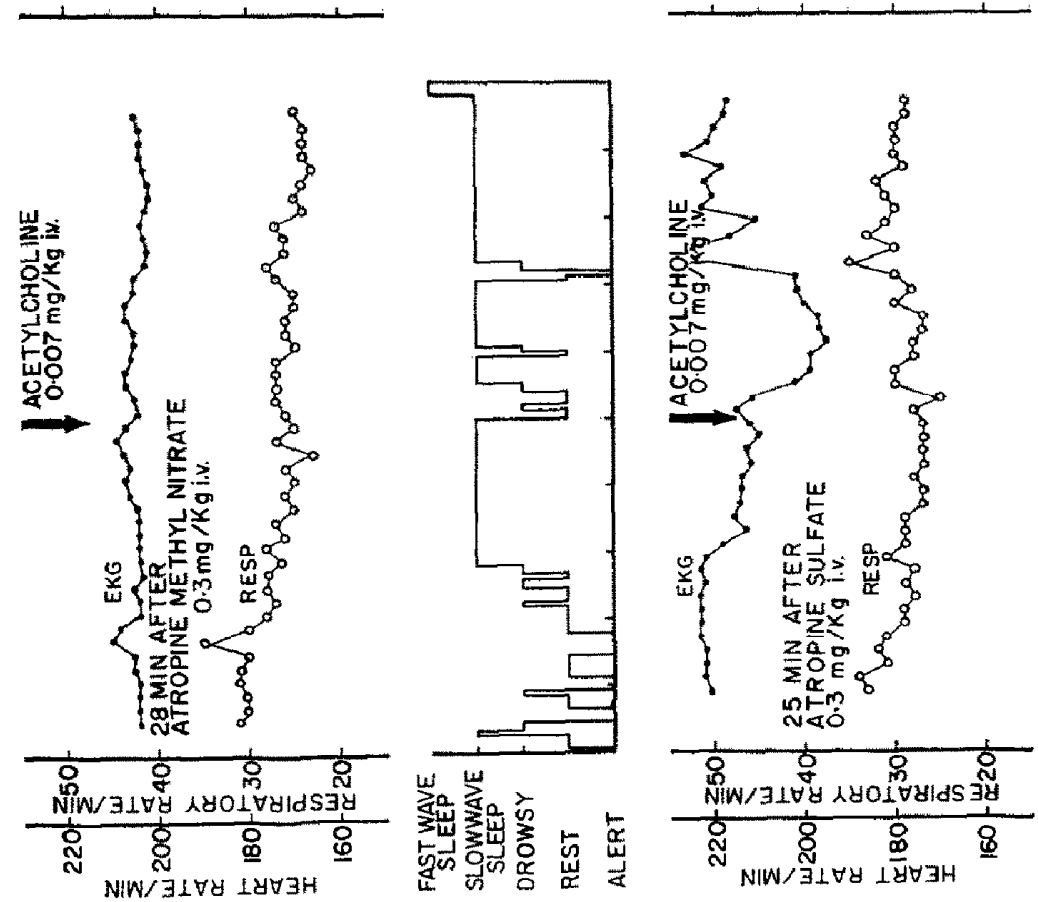
西品。

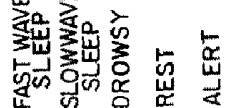

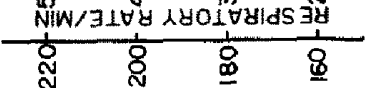

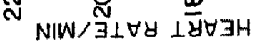

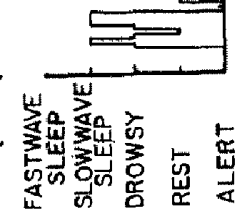


by various cholinergic antagonists. It can be seen that methyl atropine completely blocked the effects of acetylcholine on both EEG and behavior. The reduction in EEG activation was highly significant $(P<0.001)$. Equal doses of atropine also markedly reduced acetylcholine-induced EEG activation. The reduction of the EEG activation response of acetylcholine by atropine was highly significant $(P<0.001$, Table 1$)$.

In contrast to the marked effect of $m$ cholinergic antagonists, $n$ ganglionic cholinergic antagonists were completely ineffective in preventing EEG activation and behavioral arousal induced by acetylcholine. Of some interest is the finding that acetylcholine-induced EEG activation following mecamylamine premedication was slightly but significantly increased $(P<0.05$, Table 1$)$.

(2) Arecoline. A dose of $0.04 \mathrm{mg} / \mathrm{kg}$ of arecoline i.v. was found to cause approximately the same decrease in blood pressure as $0.007 \mathrm{mg} / \mathrm{kg}$ of acetylcholine in decamethoniumimmobilized cats. This dose of arecoline caused behavioral excitement such as elevation of the animal's head, standing up, looking around and walking within a few sec after injection. The typical EEG and physiological effects of arecoline are illustrated in Fig. 4.

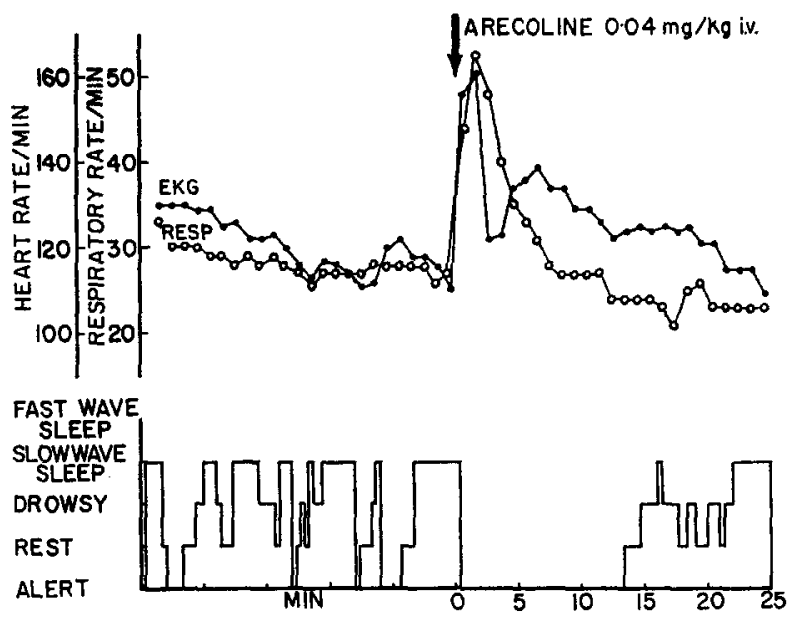

FIG. 4. Graph of the effects of arecoline.

Shortly after injection during slow wave sleep, arecoline produced marked behavioral arousal and EEG activation which lasted appoximately $12 \mathrm{~min}$. In a total of eight cats the mean duration \pm S.E. of arecoline induced EEG activation was $11.9 \pm 0.8 \mathrm{~min}$ (Table 1). Subsequently, the cats lapsed into the drowsy and slow wave sleeping state. Heart rate increased. At the same time other autonomic responses such as salivation and slight mydriasis were observed. The EEG usually activated prior to behavioral arousal. This was particularly evident in the hippocampal lead which showed marked theta wave activity.

The effects of $m$ cholinergic antagonists on the actions of arecoline are plotted graphically for the same cat in Fig. 5. After premedication with methyl atropine, characteristic EEG activation was reduced slightly, but the reduction was not statistically significant (Table 1). In contrast to the relative lack of effects of methyl atropine, atropine itself produced almost complete blockade of the EEG and behavioral manifestations of arecoline. In contrast to the marked effectiveness of atropine in blocking arecoline-induced 

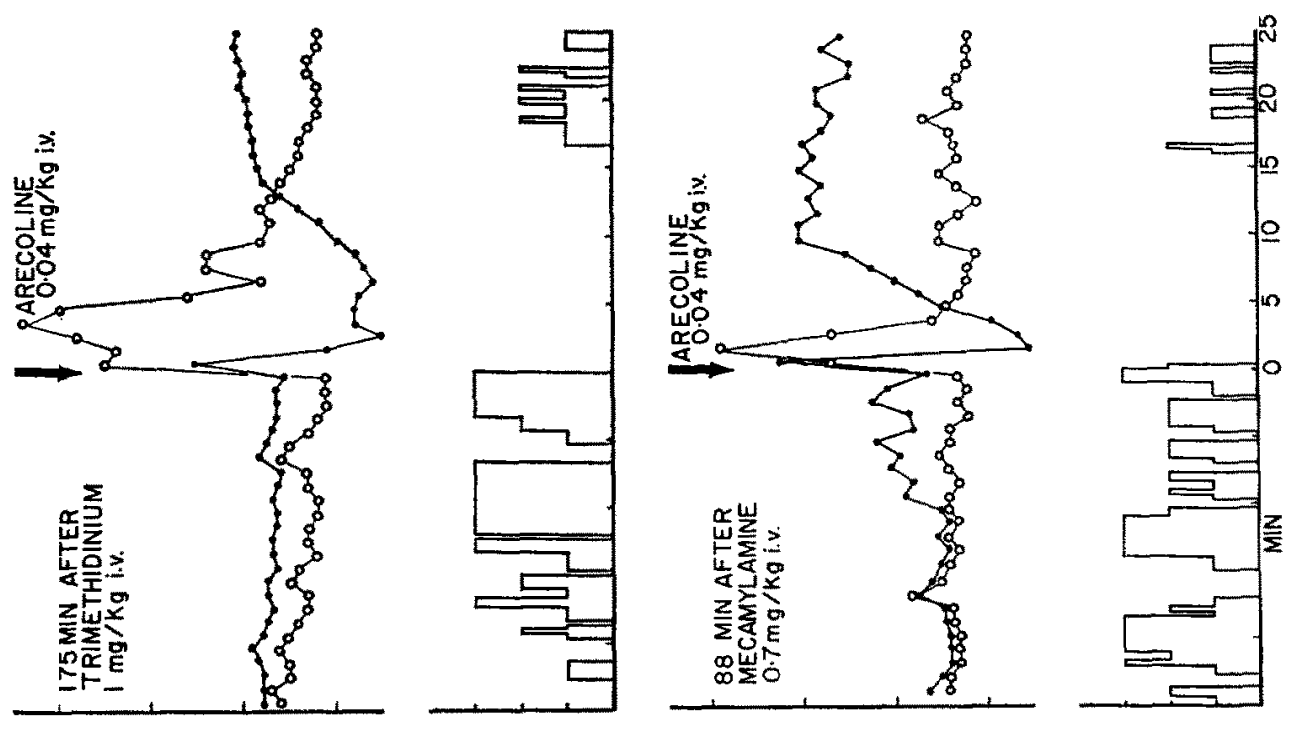

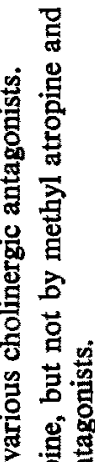
흥
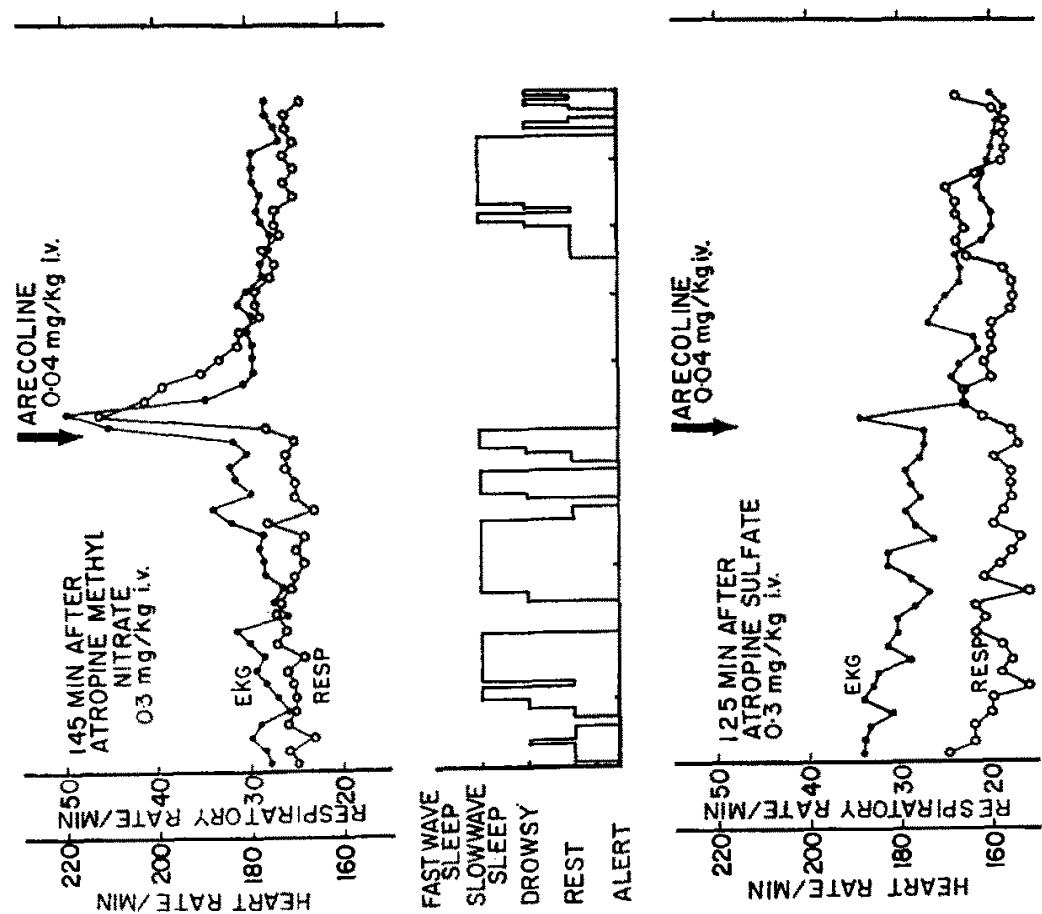

() 글
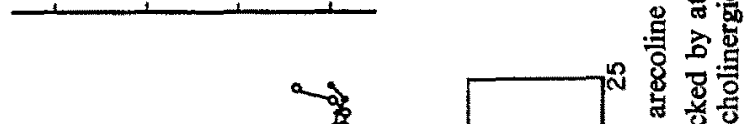

\& 8

落

으 형

용

क

ก 홍

0

娄

葛

i

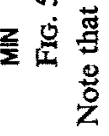

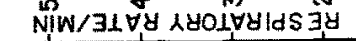

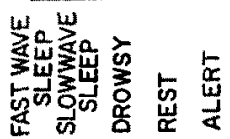


EEG activation, trimethidinium and mecamylamine had no significant effects (Fig. 5 and Table 1).

(3) Pilocarpine. Doses of $0 \cdot 15 \mathrm{mg} / \mathrm{kg}$ of pilocarpine caused EEG activation of approximately the same duration as that produced by $0.04 \mathrm{mg} / \mathrm{kg}$ of arecoline. This dose of pilocarpine produced less hypotension than arecoline. After administration of pilocarpine to the cat in slow wave sleep, evident behavioral arousal such as picking up the head, standing and walking were observed. At the same time slight mydriasis, salivation and lacrimation were present. The drug produced EEG and behavioral arousal for approximately 13 min which was accompanied by an initial bradycardia, subsequent tachycardia and tachypnea (Fig. 6). EEG activation was seen in all leads with particularly prominent

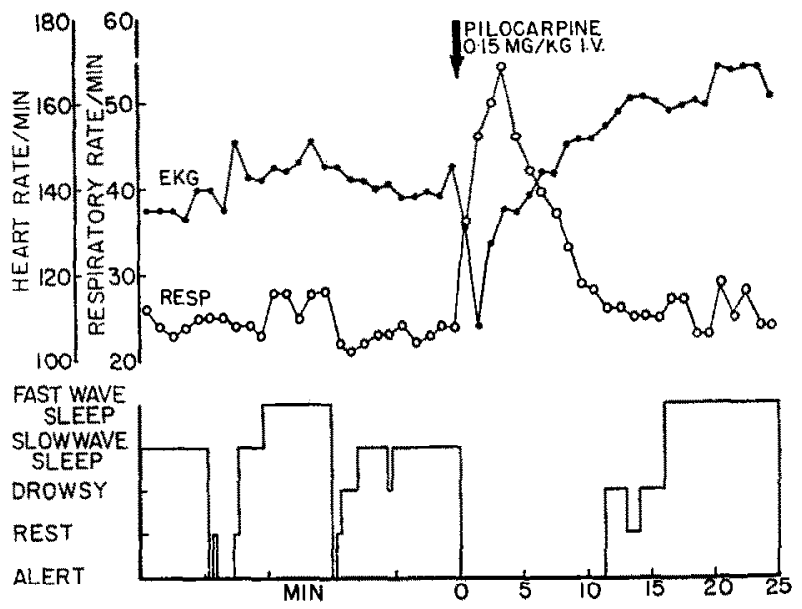

FiG. 6. Graph of the effects of pilocarpine.

hippocampal theta waves. In eight cats the mean duration \pm S.E. of pilocarpine-induced EEG activation was $13.3 \pm 1.3 \mathrm{~min}$ (Table 1). Subsequently, the cats lapsed into the resting state. Surprisingly, fast wave sleep sometimes appeared right after the resting state. Within 25 min after injection the duration of fast wave sleep increased significantly compared with saline controls $(P<0.05)$. In Fig. 7 are illustrated graphically the effects of various pretreatments on pilocarpine-induced EEG activation and other vital signs in the same cat. It can be observed that the effects of pilocarpine were markedly reduced by methyl atropine although EEG activation was still evident. The mean duration \pm S.E. of pilocarpine-induced EEG activation responses in six cats was reduced to $2.3 \pm 0.2 \mathrm{~min}$ $(P<0.001$, Table 1). The induced bradycardia, tachycardia, tachypnea, micturition, salivation, etc. were completely blocked. In contrast to methyl atropine, atropine completely prevented the blood pressure, EEG and behavioral manifestations of pilocarpine. On the other hand the $\boldsymbol{n}$ ganglionic cholinergic antagonists trimethidinium and mecamylamine did not decrease the duration of EEG activation. In fact following mecamylamine the duration of EEG activation was significantly increased $(P<0.01$, Table 1$)$.

(4) Physostigmine. This compound in a dose of $0.05 \mathrm{mg} / \mathrm{kg}$ produced significant EEG and behavioral arousal. This dose did not interrupt slow wave sleep immediately. The mean latency time \pm S.E. after injection for EEG activation was $2.6 \pm 0.3 \mathrm{~min}$. Maximal 

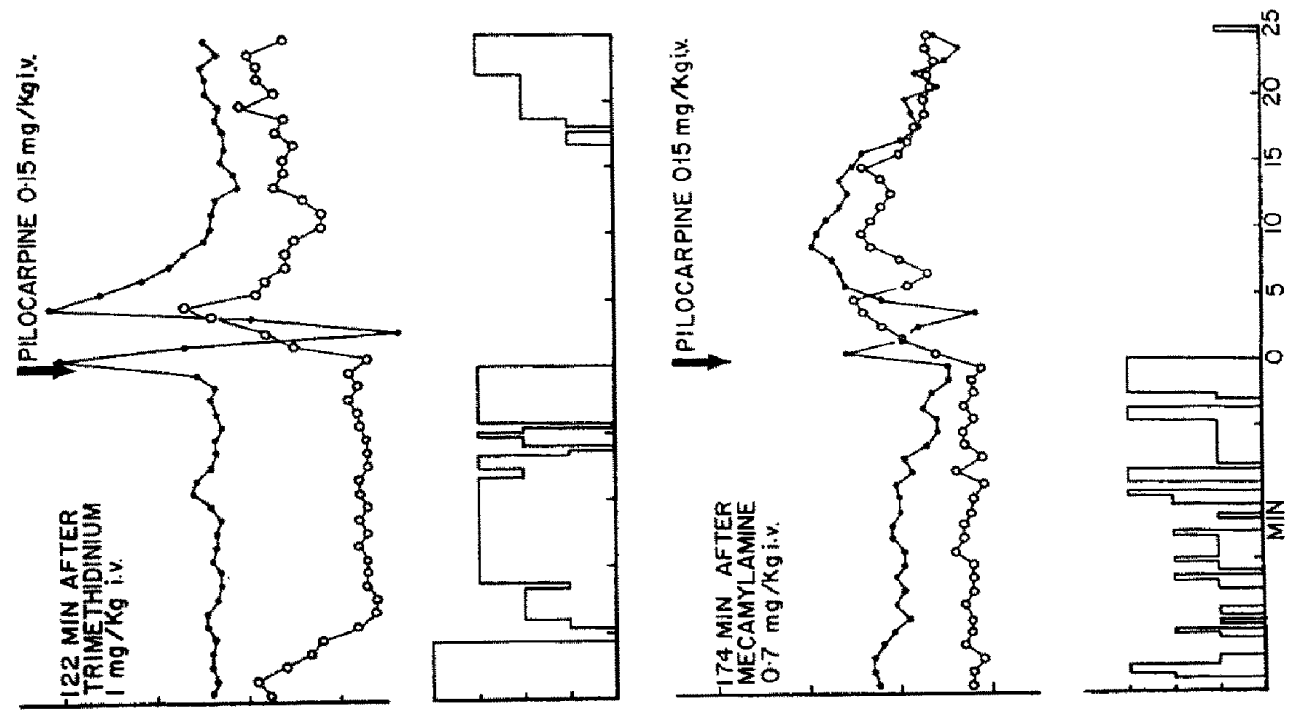

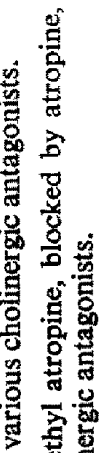

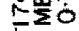
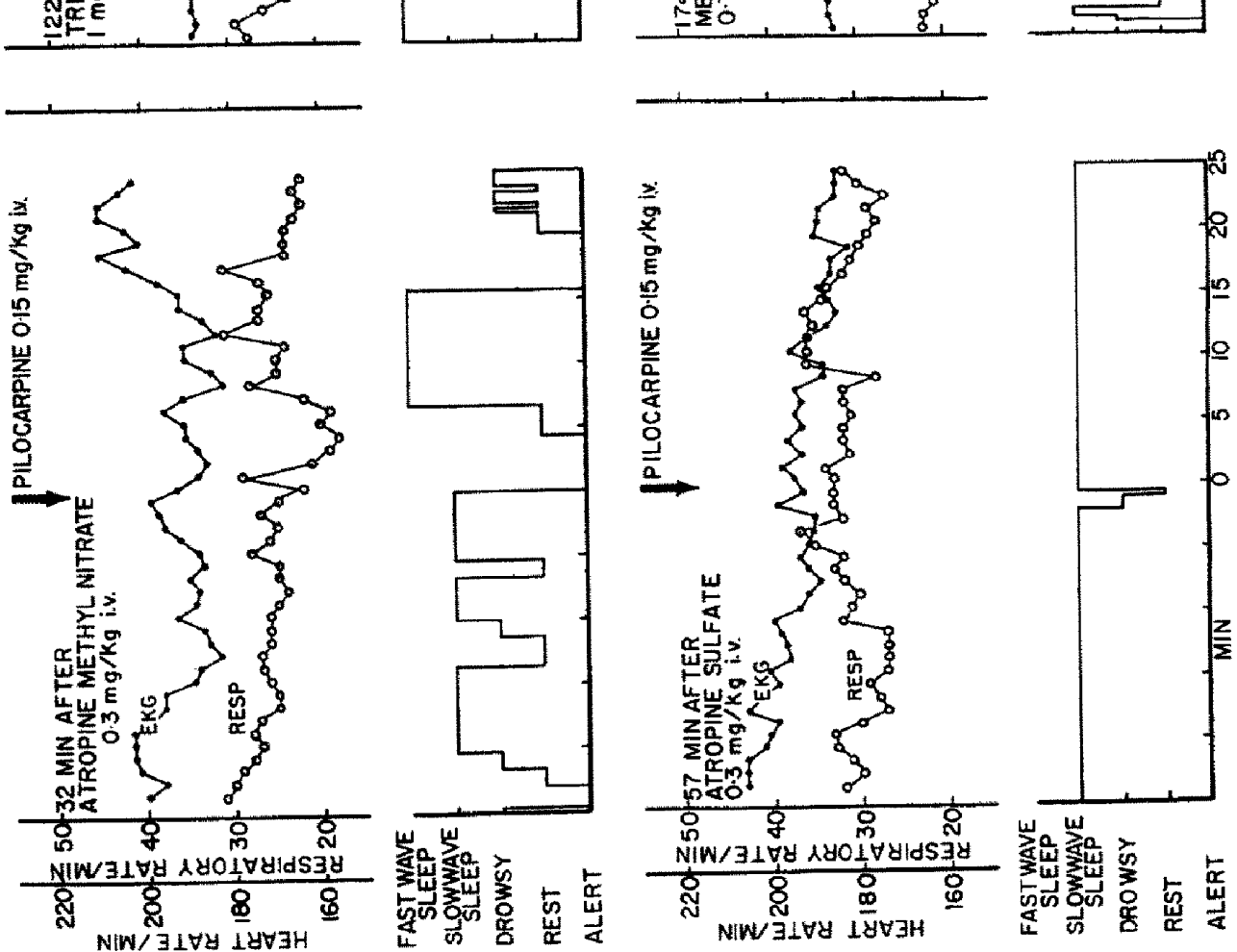

NWW $\exists 1 V y+\bar{d} V 3 H$

B

उㅎํㅇ

든

8

2.

政

苋焉

.

证

을

둥

语

范 
activation occurred 8-16 min after i.v. administration. Behaviorally the cat awakened, picked up his head, looked around and showed evident mydriasis. The response to external stimuli such as noise was exaggerated. Heart rate and respiratory movements increased in relationship to the degree of behavioral arousal and EEG activation. The effects of physostigmine are illustrated as a graphic plot in Fig. 8. Approximately 25 to $30 \mathrm{~min}$ following drug injection the cat returned toward a normal state behaviorally, although EEG activation persisted for $31.6+2 \cdot 2 \mathrm{~min}$. After physostigmine the drowsy state was
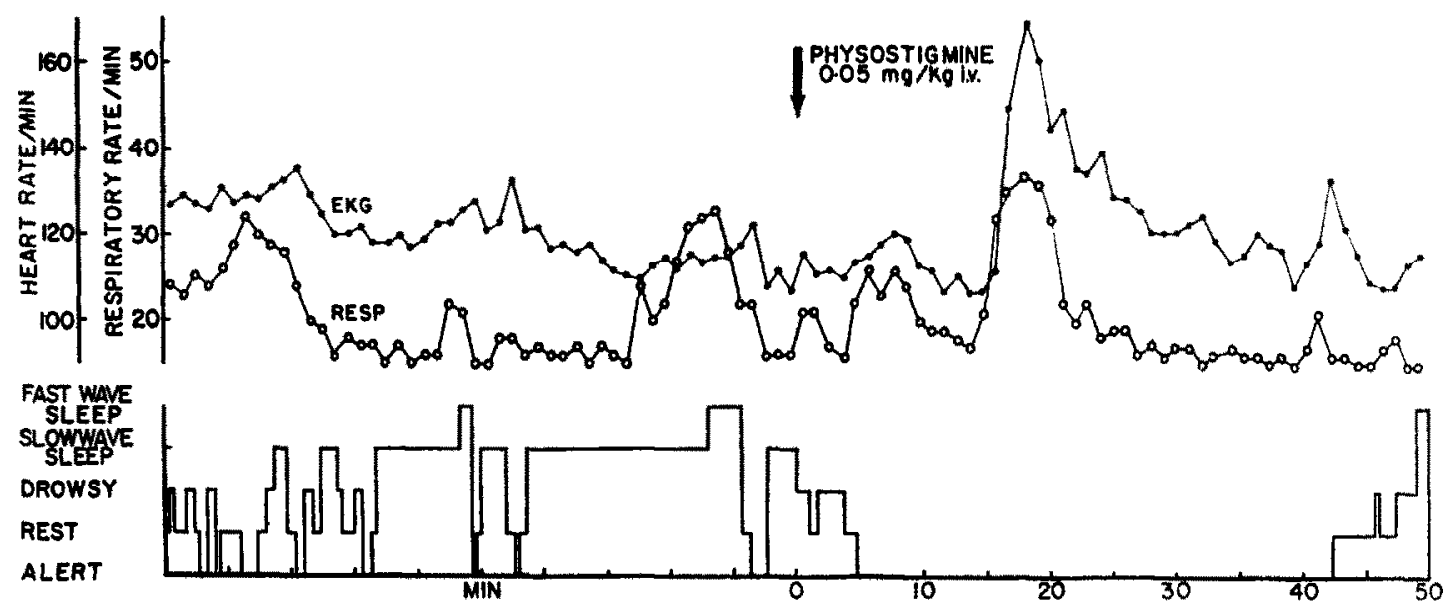

Fig. 8. Graph of the effects of physostigmine.

Note the latency before EEG and behavioral arousal following physostigmine. Approximately $48 \mathrm{~min}$ after injection fast wave sleep began from the drowsy state.

sometimes followed by fast wave sleep, although no significant increase in fast wave sleep was noted within 50 min after i.v. injection.

Figure 9 illustrates the effects of pretreatment with $m$ cholinergic antagonists on physostigmine activation in the same cat. After methyl atropine, EEG and behavioral arousal produced by physostigmine was still present but significantly reduced. The mean duration of EEG activation \pm S.E. was reduced to $22.9 \pm 3.2 \min (P<0.05$, Table 1$)$. In contrast atropine markedly reduced physostigmine-induced EEG activation and behavioral arousal. During the peak effect of physostigmine, approximately $16 \mathrm{~min}$ after i.v. injection, the amount of slow wave sleep was decreased. However, the animals still showed a drowsy pattern. Physostigmine-induced EEG activation following atropine pretreatment was markedly reduced to $1.3 \pm 0.5 \mathrm{~min}(P<0.001$, Table 1$)$. In contrast to the effectiveness of $m$ cholinergic antagonists, the $n$ ganglionic cholinergic antagonists trimethidinium and mecamylamine did not significantly alter the EEG or behavioral manifestations of physostigmine in the same cat (Fig. 10 and Table 1).

(5) Nicotine. The i.v. injection of small doses of $0.02 \mathrm{mg} / \mathrm{kg}$ of nicotine caused consistent EEG activation and behavioral arousal. The mean duration \pm S.E. of nicotineinduced EEG activation in eight cats was $4.7 \pm 0.5 \mathrm{~min}$. Subsequently, the animals fell into slow wave and/or fast wave sleep. The effects of nicotine on the awake-sleep cycle of the cat are illustrated graphically in Fig. 11. Marked respiratory stimulation and EKG 

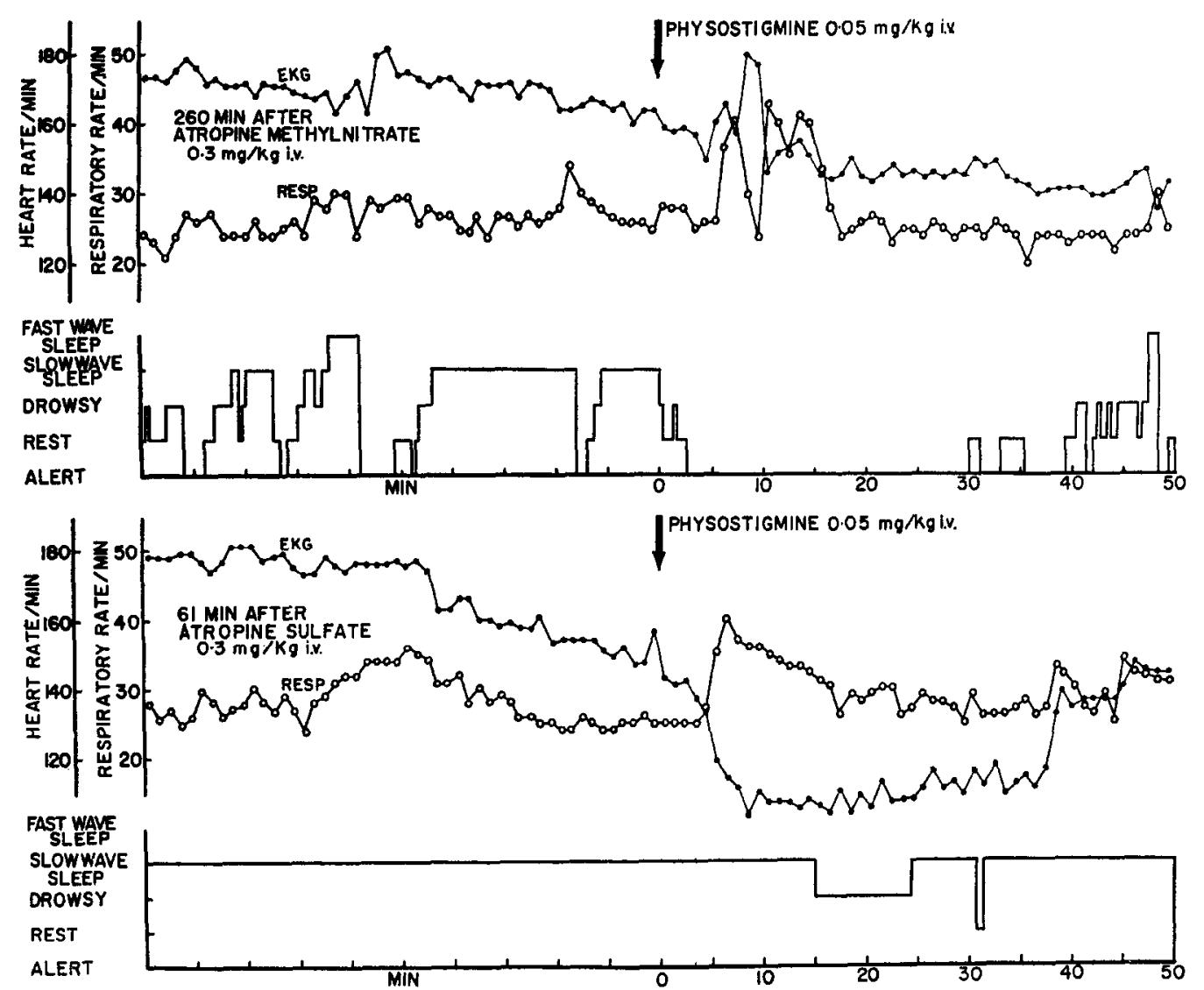

FIG. 9. Modification of the effects of physostigmine by $m$ cholinergic antagonists.

Note that the effects of physostigmine were reduced slightly by methyl atropine, but blocked by atropine.

alterations were noted during the brief period of EEG and behavioral activation. The effects of pretreatment with various cholinergic antagonists on the nicotine-induced responses are plotted graphically in Fig. 12. After methylatropine, nicotine-induced tachypnea and tachycardia were still evident. On the other hand nicotine-induced bradycardia was blocked. EEG and behavioral arousal due to nicotine was not reduced significantly (Table 1). The effects of atropine pretreatment were somewhat similar to those of methyl atropine for nicotine-induced neocortical desynchronization and behavioral arousal. EEG neocortical desynchronization was reduced slightly but was still clearly evident. In contrast, hippocampal and amygdaloid activation patterns were not as clearly present, and frequently were dissociated from neocortical desynchronization. Atropine pretreatment reduced the mean duration \pm S.E. of nicotine-induced neocortical activation to $2 \cdot 1 \pm 0.3 \mathrm{~min}$. This effect was statistically significant $(P<0.01)$. As reported previously (Yамамото and Domino, 1965) the $n$ cholinergic blockers, mecamylamine and trimethidinium, showed differential effects. Trimethidinium caused a slight reduction in nicotine 

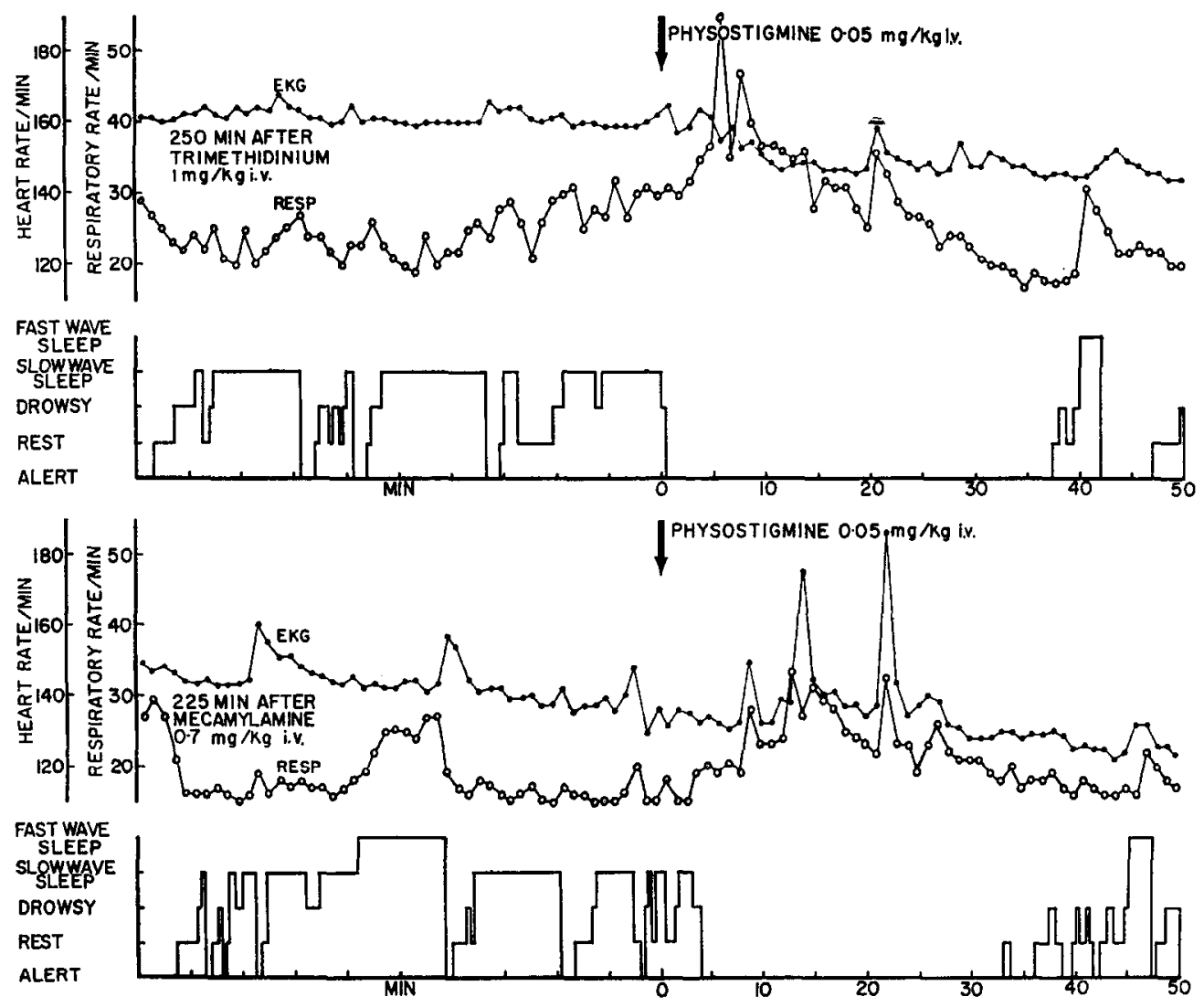

FIG. 10. Lack of significant modification of physostigmine effects by $n$ ganglionic cholinergic antagonists.

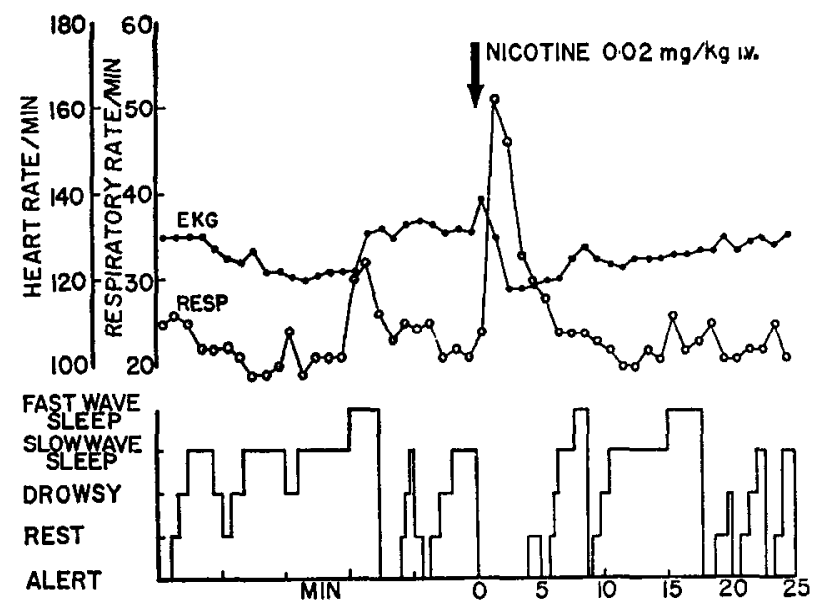

Fig. 11. Graph of the effects of nicotine. 

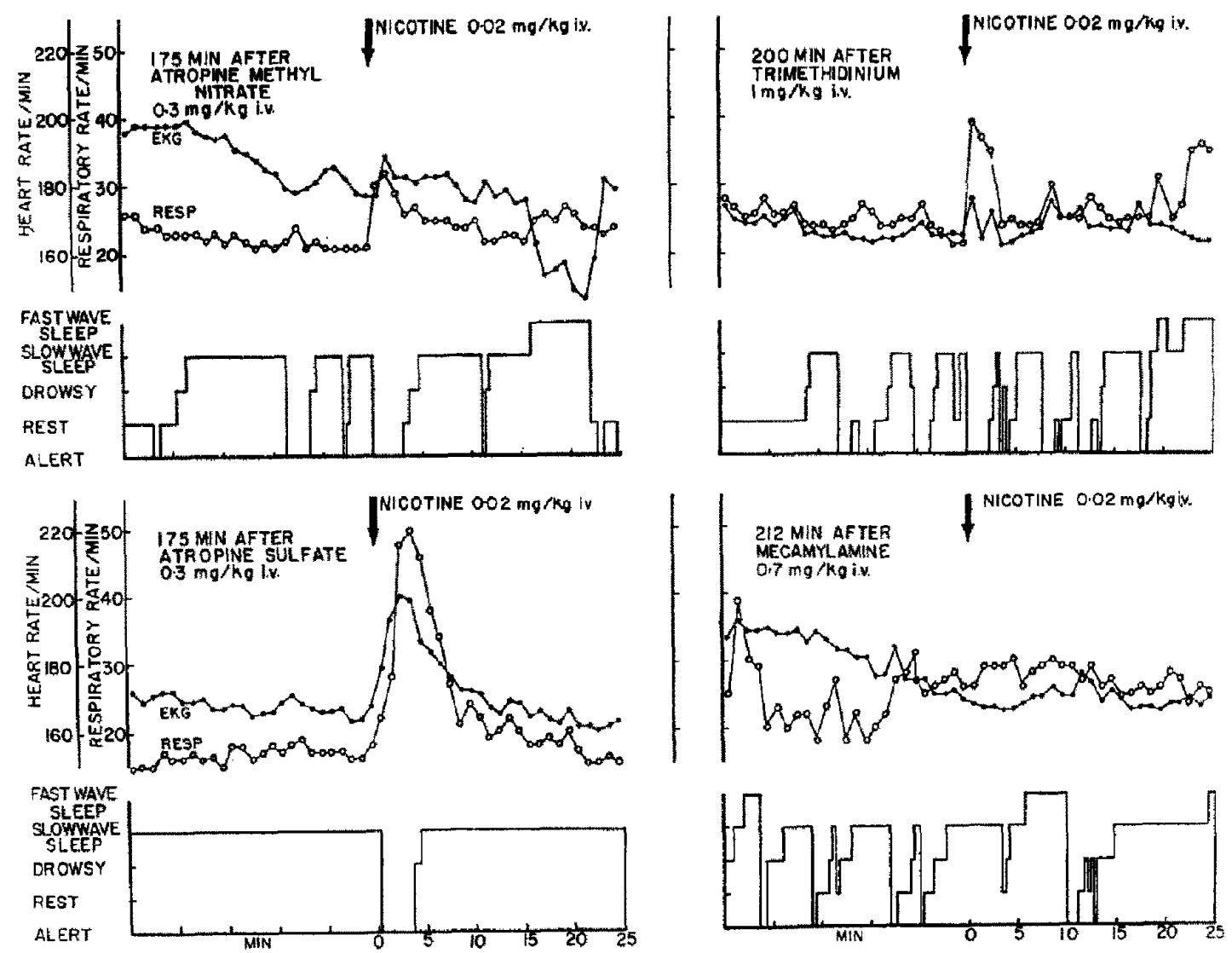

Fig. 12. Modification of the effects of nicotine by various cholinergic antagonists.

Note that the EEG effects of nicotine were not blocked by methyl atropine, atropine and trimethidinium, but were completely blocked by mecamylamine.

induced EEG and behavioral activation. In contrast, mecamylamine completely blocked the actions of nicotine (Fig. 12 and Table 1).

Relationship between some cholinergic agonists and fast wave sleep

As reported previously (Yamamoto, 1959), the stage of fast wave sleep usually is preceded by slow wave sleep. During the present study it was observed that particularly following the administration of pilocarpine and physostigmine, this regular sequence from slow wave to fast wave sleep was altered. Frequently after these $m$ cholinergic agonists the stage of fast wave sleep started from the resting or drowsy state. In one cat, given a massive dose of $1 \mathrm{mg} / \mathrm{kg}$ of pilocarpine, fast wave sleep began from the awake stage without any intermediate slow wave stage. The duration of fast wave sleep also was significantly increased following pilocarpine in doses of $0.15 \mathrm{mg} / \mathrm{kg}(P<0.05)$. During the recovery phase, after the long period of EEG activation and behavioral arousal caused by physostigmine, fast wave sleep was occasionally seen starting from the drowsy state. For 50 min following physostigmine there was no increase in duration of fast wave sleep over saline injection. 


\section{Dissociation of EEG and gross behavior}

The common observation of a dissociation between EEG and gross behavior was also seen in this study. This was especially evident after atropine and physostigmine. Of special importance was the fact that in this investigation the cholinergic agonists were always given i.v. when the cats were in obvious slow wave sleep as identified by the EEG and gross behavior. Shortly thereafter the EEG activating effects of the various cholinergic agonists were accompanied by gross behavioral arousal. EEG dissociation from gross behavior was usually seen during this early phase or subsequently during recovery. In some cases, especially after physostigmine and pilocarpine, the cats lapsed into fast wave sleep. Without limbic EEG and polygraphic recordings of EMG, heart rate and respiration, it would have been difficult to define at least one aspect of EEG dissociation from gross behavior, namely fast wave sleep.

\section{DISCUSSION}

The purpose of this research was to test several hypotheses: (1) That the EEG desynchronizing effects of various $m$ and $n$ cholinergic agonists were accompanied by behavioral arousal, or (2) such EEG desynchronization represented a stage of fast wave sleep and (3) by the use of various $m$ and $n$ cholinergic antagonists with differential abilities to penetrate the blood-brain barrier, it would be possible to conclude whether the actions of various cholinergic agonists were primarily central or peripheral. There are considerable sources of error in this method of research. Perhaps the most important criticism is that any study of agonist-antagonist interactions should be quantitative and involve doseresponse relationships. It has been pointed out by TRENDELENBERG (1963) that false conclusions can be drawn in studies in which single doses of agonists and antagonists are used. In view of the lack of a simple and meaningful method for quantifying EEG activity, no direct dose-effect relationships were obtained. In this study the doses of various cholinergic agonists used produced nearly maximal EEG and behavioral manifestations. In contrast, the doses chosen for the cholinergic antagonists did not significantly interfere with the awake-sleep cycle of the cat. It should be noted that the doses chosen for the various antagonists were insufficient to block completely peripheral autonomic effects such as alteration in blood pressure or heart rate. Another objection to the experimental design is the variable interval of $20-260 \mathrm{~min}$ after pretreatment with a cholinergic antagonist. This objection is not valid in the case of long-acting drugs such as trimethidinium. However, with the shorter acting antagonists it is obvious they cannot have the same degree of effect from 20-260 min after injection. The cholinergic agonists were given in a random time interval after pretreatment and somewhat similar effects were obtained, indicating that the cholinergic antagonists were still active. Since maximal peripheral blocking doses could not be given because of induced alterations in the sleep cycle, these results should be interpreted as indicating relative degrees of central vs. peripheral blockade.

In spite of these limitations several predictions were confirmed experimentally. Acetylcholine is a highly charged molecule that should not easily penetrate the blood-brain barrier. Its actions on EEG activation and behavioral arousal should be primarily peripheral in origin. These effects should be blocked by atropine and methyl atropine equally well. This in fact was shown. The fact that such small doses of methyl atropine did not completely antagonize the peripheral cardiovascular effects of acetylcholine while blocking the EEG effects indicates that the EEG effects must be primarily peripheral in origin. 
These data are in agreement with the findings of NAKAO et al. (1956) that the EEG effects of i.v. acetylcholine are greatly reduced by sino-aortic denervation. Cholinergic agonists and antagonists which easily penetrate the blood-brain barrier on the basis of being less highly charged should have both central as well as peripheral actions. It is well recognized that the blood-brain barrier is not absolute. Although PaUl David et al. (1960) have shown that methyl atropine in sufficient amount produces EEG slow waves, the doses chosen in this study were clearly below those for significant central actions. The actions of the various $m$ cholinergic agonists such as acetylcholine, arecoline, pilocarpine, and physostigmine, were blocked primarily by the $m$ cholinergic antagonists and not significantly reduced by the $n$ cholinergic antagonists. Mecamylamine actually enhanced the EEG desynchronizing effects of some $m$ cholinergic agents. In contrast, neocortical activation due to nicotine was not significantly affected by methyl atropine but was reduced to approximately half the duration by atropine. An interesting dissociation between neocortical and limbic structures was observed following atropine pretreatment and subsequent nicotine administration. The results are similar to those reported by Torir and WIKLER $(1964,1966)$ for electrical stimulation of the midbrain reticular formation or posterior hypothalamus. It is well known that large doses of atropine effectively block neocortical activation due to a variety of stimuli or drugs (Domino and HuDson, 1958; WhITE and Boyajy, 1959; and WhITE and Daugneault, 1959). This suggests that the terminal neurons for neocortical activation must involve $m$ cholinergic synapses.

The data of this study are consistent with the concept that there are important $m$ and, to a less extent, $n$ cholinergic receptor sites in EEG neocortical and limbic system activation. Furthermore, the initial effects of cholinergic agonists are associated primarily with behavioral arousal. It has been reported previously by WIKLER (1952) and BRADLEY and ELKES (1957) and others that cholinergic antagonists and agonists produce EEG dissociation from gross behavior. While similar findings were noted in the present study, it should be pointed out that effective doses of physostigmine and other cholinergic agonists produce initial clear-cut behavioral arousal. Furthermore, it should be pointed out that the findings of BRADLEY and ELKES (1957) and others with cholinergic agonists were made at a time when the stage of fast wave sleep was not generally appreciated. It would appear that in some instances investigators may have been observing fast wave sleep and did not recognize it. The findings of the present study strengthen the concept of a definite but not invariable relationship between EEG and behavior, especially during arousal from slow wave sleep. This relationship can be disrupted by atropine, for example.

JOUVET (1961) reported that physostigmine increased the duration of fast wave sleep. In our experience the predominant effect of physostigmine was behavioral arousal and EEG activation. Only after $\frac{1}{2} \mathrm{hr}$ or more following physostigmine injection (during the recovery phase) was fast wave sleep seen. The total amount of fast wave sleep for 50-min after physostigmine injection, however, was not significantly enhanced over that after saline solution. A particularly interesting finding was that fast wave sleep could occur from an initial baseline of drowsiness. Pilocarpine produced a significant increase in the duration of fast wave sleep and the same phenomenon in which fast wave sleep was preceded by the resting or drowsy state rather than slow wave sleep. The findings of this study suggest an important role of cholinergic mechanisms in modulating some components of fast wave sleep. 


\section{REFERENCES}

Bradley, P. B. and ElKes, J. (1957). The effects of some drugs on the electrical activity of the brain. Brain 88: $77-117$.

Bradley, P. B. and Nicholson, A. N. (1962). The effect of some drugs on hippocampal arousal. Electroenceph. clin. Neurophysiol. 14: 824-834.

DenisenKo, P. P. (1961). Cholinergic and adrenergic systems in the reticular formation of the midbrain and the reaction of activation in the cortex. Sechenov. Physiol. J. USSR (Eng) 47: 609-616.

DEnISENKo, P. P. (1962). Influence of pharmacological agents upon cholinoreactive and adrenoreactive systems of the rcticular formation and other regions of the brain. Proc. 1st int. Pharmacol. Meet. Pharmacological analysis of central nervous action (W. D. M. PATon, Ed.), Pergamon Press.

Domino, E. F. (1955). A pharmacological analysis of the functional relationship between the brainstem arousal and diffuse thalamic projection system. J. Pharmac. exp. Thér. 115: 449-463.

Domino, E. F. and Hudson, R. D. (1958). Observations on the pharmacological actions of the isomers of atropine. J. Pharmac. exp. Thér. 127: 305-312.

Domino, E. F., Dren, A. T. and Yamamoto, K. (1967). Pharmacologic evidence for cholinergic mechanisms in neocortical and limbic activating systems. Progress in Brain Research, Elsevier, Amsterdam (In press).

ILYUTCHENOK, R. YU (1962). The role of cholinergic systems of the brainstem reticular formation in the mechanism of central effects of anticholinesterase and cholinolytic drugs. Proc. 1st int. Pharmacol. Meet. Pharmacological analysis of central nervous system. (W. D. M. PATon, Ed.) 8: 211-216.

ILYUTCHENOK, R. YU. and MASHKovSKII, N. P. (1961). Electrophysiological data on cholineractive elements of the reticular formation of the brainstem. Sechenov. Physiol. J. USSR 47: 1352-1359.

ILYUTCHENOK, R. YU. and OSTROVSKAYA, R. U. (1962). The role of mesencephalic cholinergic systems in the mechanism of nicotine activation of the electroencephalogram. Bull. exp. Biol. Med. U.S.S.R. 54: 753-757.

JASPER, H. H. and AJMONE-MARSAN, C. (1954). A stereotaxic atlas of the diencephalon of the cat (Ottawa).

Jouvet, M. (1961). Telencephalic and rhombencephalic sleep in the cat. Ciba Foundation Symp. Nature Sleep 188-206.

KNAPP, D. E. and Domino, E. F. (1962). Action of nicotine on the ascending reticular activating system. Int.J. Neuropharmacol. 1: 333-351.

Mikhelson, M. J. (1961). Pharmacological evidences of the role of acetylcholine in the higher nervous activity of man and animals. Activitas nerv. sup. 3: 140-147.

NakaO, H., Ballim, H. M. and Gellhorn, E. (1956). The role of the sinoaortic receptors in the cerebral cortex. Electroenceph. clin. Neurophysiol. 8: 413-420.

Paul David, J., Riehl, J. L. and UnNa, K. R. (1960). Quantification of effects of depressant drugs on EeG activation response. J. Pharmac. exp. Thér. 129: 69-74.

Rinaldi, F. and HIMwich, H. (1955). Cholinergic mechanism involved in function of mesodiencephalic activating systems. Archs. Neurol. Psychiat. 73: 396-402.

Snider, R. S. and Niemer, W. T. (1961). A Stereotaxic Atlas of the Cat Brain. The University of Chicago Press, Chicago.

TORII, S. and WIKLER, A. (1965). Effects of atropine on electrical activity of neocortex and hippocampus in cat. Fed. Proc. Fedr. Am. Socs exp. Biol. $24: 516$.

TORII, S. and WIKLER, A. (1966). Effects of atropine on electrical activity of hippocampus and cerebral cortex in cat. Psychopharmacologia 9: 189-204.

Trendelenberg, U. (1963). Supersensitivity and subsensitivity to sympathomimetic amines. Pharmacol. Rev. 15: 225-276.

Valdman, A. V. (1961). The Pharmacology of Reticular Formation and Synaptic Transmission. p. 432 Leningrad.

Valdman, A. V. (1963). Problems of Pharmacology of Reticular Formation and Synaptic Transmission. p. 416. Leningrad.

Villarreal, J. E. and Domino, E. F. (1964). Evidence for two types of cholinergic receptors involved in EEG desynchronization. Pharmacologist 6: 192.

WhITE, R. P. and BOYAJY, L. D. (1959). Comparison of physostigmine and amphetamine in antagonizing the EEG of CNS depressants. Proc. Soc. exp. Biol. Med. 102: 479-483.

White, R. P. and Daugneault, E. A. (1959). The antagonism of atropine to the EEG effects of adrenergic agents. J. Pharmac. exp. Thér. 125: 339-346.

WIKLER, A. (1952). Pharmacologic dissociation of behaviour and EEG "sleep patterns" in dogs: morphine, n-allylnormorphine, and atropine. Proc. Soc. exp. Biol. Med. 79: 261-265.

YAmAMoto, K. (1959). Studies on the normal EEG of the cat. Comparison between the EEG of fixed cats and unfixed cats seen from the skull and subcortical leads in various consciousness levels and the corresponding behavior. Ann. Rep. Shionogi Res. Lab. (Osaka, Japan) 2: 1125-1164.

Yamamoto, K. and Domino, E. F. (1965). Nicotine-induced EEG and behavioral arousal. Int. J. Neuropharmacol. 4 : 359-373. 